\title{
Utilização do Monóxido de Carbono como indicador da qualidade do ar na Universidade Federal de Campina Grande.
}

\author{
Fernanda Siqueira Lima* (Graduanda em Engenharia Química na Universidade Federal de \\ Campina Grande - UFCG) \\ Adalício Uzeda Antunes J únior; (Mestrando em Engenharia Química na Universidade Federal de \\ Campina Grande - UFCG) \\ Maria Isabel do Bú Araújo; (Graduanda em Engenharia Química na Universidade Federal de \\ Campina Grande - UFCG) \\ Maria Rosiane de Almeida Andrade; (Mestranda em Engenharia Química na Universidade \\ Federal de Campina Grande - UFCG) \\ *Email: fsl nanda@hotmail.com
}

Resumo:

A qualidade do ar é um padrão indicativo das condições atmosféricas de uma determinada região e através dela, é possível determinar a qualidade de vida dos habitantes. Um país ou uma cidade que possui um índice de qualidade do ar (IQAr) classificado como inadequado, consequentemente terá uma população com sérios problemas de saúde (tosse, cansaço, irritação nos olhos, nariz e garganta). Os veículos (carros, ônibus, caminhões, etc) e motos são considerados fontes expressivas do monóxido de carbono, já que até mesmo estacionados são fontes emissoras, representando grande parcela desse gás na atmosfera. Estudos mostram que as emissões veiculares são responsáveis pelo grau de poluição nas médias e grandes cidades.

Atualmente o Brasil possui 2.378 instituições de ensino superior (IES), que se distribuem em todo país. Essas IES são organizações sociais e como tal exprimem de maneira determinada a estrutura e o modo de funcionamento da sociedade como um todo. Esse perfil, as levam a serem comparadas com pequenos centros urbanos, envolvendo uma infraestrutura comparada a municípios de médio e pequeno porte. Neste contexto, a Universidade Federal de Campina Grande (UFCG), é uma IES de relevância para o Estado da Paraíba, visto que, possui um fluxo diário médio de 11.873 pessoas, representando 3,07\% dos 386.000 habitantes de Campina Grande, cuja frota veicular é de 147.423 veículos e 78.551 motos. Os veículos são considerados fontes móveis de poluição atmosférica, responsáveis pela geração de monóxido de carbono (CO), um gás que em concentrações elevadas causa efeito negativo à saúde.

Palavras-chave:

Universidades; Emissão de Gases. 


\section{A importância da UFCG no âmbito da cidade de Campina Grande}

Segundo o Instituto Nacional de Estudos e Pesquisas Educacionais (INEP, 2010), atualmente, o Brasil conta com 2.378 Instituições de Ensino Superior (IES). Os últimos dados revelam o crescimento em número das IES e com isso uma série de questionamentos, pois, conforme Martins (2000), tudo leva a crer que as universidades são fundamentais para o desenvolvimento do país, porque têm se revelado um espaço destacado no processo de ampliação das oportunidades educacionais, e se tornaram um ambiente central e fundamental na discussão e divulgação de questões relevantes do país e de nossa época, conduzidas por uma diversidade de perspectivas analíticas.

Isso se deve, segundo Chauí (2003), as universidades terem um sistema de organização social e exprimem de maneira determinada a estrutura e o modo de funcionamento da sociedade como um todo. Completam Tauchen e Brandli (2006), que as universidades podem ser comparadas com pequenos núcleos urbanos, envolvendo diversas atividades de ensino, pesquisa, extensão e atividades referentes à sua operação por meio de bares, restaurantes, alojamentos, centros de conveniência, entre outras facilidades. Além disto, um campus precisa de infraestrutura básica, redes de abastecimento de água e energia, redes de saneamento e coleta de águas pluviais e vias de acesso.

Diante de tamanha proporção adquirida pelos campis universitários, Tauchen e Brandli (2006) afirmam ainda que há diversas consequências das atividades de operação dos mesmos, dentre elas: a geração de resíduos sólidos e efluentes líquidos, consumo de recursos naturais e poluição atmosférica.

Estes poluentes, em conjunto ou em separado, são capazes de causarem sérios impactos ambientais para os meios bióticos e abióticos. Destacando-se a poluição atmosférica, como um dos mais sérios tipos de poluição causada pelo homem, haja vista, muitas vezes o poluente atmosférico não ser perceptível a visão e ao olfato.

Portanto, observa-se que as universidades desempenham um papel muito importante na sociedade, haja vista, a necessidade de apresentar uma coerência de postura, inclusive na administração e no sistema de gestão do meio ambiente.

Dentro dessa ótica, inclui-se a Universidade Federal de Campina Grande (UFCG) na cidade de Campina Grande (Campus I). O Campus I é uma Instituição de Ensino Superior (IES) de relevância para o Estado, visto que, está inserida na segunda maior cidade do interior do nordeste com aproximadamente 386.000 habitantes, onde a universidade conta com 738 docentes, 494 servidores, 366 terceirizados, 8.994 alunos de graduação e 1.281 alunos de pós-graduação, perfazendo um total de 11.873 pessoas que diariamente vem às suas dependências para trabalhar ou estudar (MARIZ, 2013). Esse montante de pessoas é maior do que o número de habitantes de diversas cidades do Estado, por exemplo, a cidade de Água Branca possui 9.449 habitantes, Areial tem 6.470 habitantes, Cabaceiras tem 5.035 habitantes e Juarez Távora possui 7.459 habitantes (Instituto Brasileiro de Geografia e Estatística - IBGE, 2013).

Portanto, o Campus I pode ser considerado de fato uma cidade universitária, gerando progresso e, também, resíduos para os meios aquático, terrestre e atmosférico. Desse modo, dentro dessa temática o Campus I deve ser inserido, haja vista, no mesmo ocorrerem, além de aulas teóricas, aulas práticas (com descarte de resíduos líquidos, sólidos e atmosféricos). Além de trafego de automóveis no seu interior e no seu entorno.

Por conseguinte, o Campus I deve ser visto também no aspecto do seu crescimento e desenvolvimento. Segundo Oliveira (2010) o crescimento e desenvolvimento das cidades fazem com que a poluição torne-se algo rotineiro na vida do ser humano e, cada vez mais, expanda suas formas: a poluição do solo com produtos químicos, orgânicos, pesticidas, agrotóxicos, óleos e outros; a poluição das águas, podendo-se destacar os metais pesados, lixo urbano, esgoto e petróleo; a poluição do ar com, por exemplo, emissões industriais, escapamentos dos veículos, queimadas, aerossóis, gerando chuvas ácidas, aquecimento global, redução na camada de ozônio, entre outras consequências.

Um dos elementos que mais tem sido agredido pelo homem é o ar. Indispensável para a vida, uma vez que não se pode deixar de respirar. Provavelmente não recebeu maiores atenções 
pelo fato de ser abundante, invisível e inodoro. Porém, ao longo da história do progresso da humanidade, suas características foram mudando (BRAGA, 2001).

A qualidade do ar urbano é determinada por um complexo sistema de fontes fixas (indústrias, queima de lixo, fornos, caldeiras, etc.) e móveis (veículos automotores e outros). O contínuo aumento das fontes poluidoras sem o devido controle tem contribuído na elevação dos níveis de poluição atmosférica. As fontes veiculares têm uma participação acentuada na degradação da qualidade do ar atmosférico, principalmente em grandes centros urbanos (TEIXEIRA, 2008).

A cidade de Campina Grande no ano 2003 contava com uma frota veicular de 41.132 e atualmente esse número está em torno 147.423, distribuído entre carros de passeio, ônibus, caminhões e 74.551 motos (DETRAN, 2014 dados atualizados - mês de junho) os quais passaram, passam e passarão no entorno e dentro do Campus I da UFCG, os quais poderão ser responsáveis por inúmeros efeitos negativos sobre a saúde dos meios bióticos e abióticos.

Entretanto, os veículos podem poluir mesmo sem estar em funcionamento, pois com o motor desligado ocorre evaporação de combustível pelo suspiro do tanque e no sistema de carburação do motor, sendo grande parte desses vapores lançada para a atmosfera. Em regiões congestionadas, o tráfego de veículos responde por cerca de $90 \%$ das emissões de monóxido de carbono (CO), 80 a 90\% das emissões de óxidos de nitrogênio (NOx), hidrocarbonetos (HC) e uma boa parcela de materiais particulados (MP), constituindo uma ameaça à saúde humana. Veículos pesados (ônibus e caminhões) são responsáveis pela maior fração das emissões de óxidos de nitrogênio $\left(\mathrm{NO}_{\mathrm{x}}\right)$ e de enxofre $\left(\mathrm{SO}_{\mathrm{x}}\right)$, enquanto que os veículos leves (automotores de passeio e de uso misto), movidos a gasolina e a álcool, são os principais emissores de CO e hidrocarbonetos (TEXEIRA, 2008). O CO, gerado principalmente por fontes móveis é bastante utilizado como indicador para caracterizar a qualidade do ar em determinado ambiente (MARIZ, 2013).

Na busca de soluções e procurando estar na vanguarda do seu tempo, inúmeras universidades têm se preocupado com a questão ambiental. Segundo Mariz (2013) desde a década de 70 várias universidades procuram implantar ações ambientais, destacando-se a Universidade Latina da Costa Rica, Universidades da Califórnia, de Winscosin, do Estado do Novo México, de Illinois e de Minnesota, nos Estados Unidos, Universidade do Vale dos Sinos (UNISINOS - Rio Grande do Sul), Universidade Federal de Santa Catarina (UFSC), Fundação Universidade Regional de Blumenau (FURB - Santa Catarina), Universidade Federal do Rio Grande (FURG), Universidade Federal do Rio Grande do Sul (UFRGS), Universidade Federal de Lavras (UFLA Minas Gerais).

As pesquisas na UFLA estão voltadas para o tratamento dos efluentes, planejamento e gestão de energia, gestão de resíduos e prevenção de incêndios, as quais estão subordinadas por uma diretoria de meio ambiente (MARIZ, 2013).

Tauchen e Brandli (2006) fizeram um levantamento de benchmarkings nacionais e internacionais de boas práticas de sustentabilidade ambiental em campus universitários, no processo de pesquisa, foram encontrados diversos casos de gestão ambiental em âmbito universitário. De um total de 42 IES pesquisadas, as ações sustentáveis que mais aparecem são o controle do consumo e reuso da água e o programa de reciclagem-gestão de resíduos, em torno de $22 \%$ dos casos, seguidos do treinamento e sensibilização dos alunos, com 19\% dos casos. Outros dois aspectos que aparecem em 16\% das IES foram a auditoria ambiental para indicar melhorias onde necessário e do diagnóstico dos impactos diretos ou significativos para o ambiente.

Já no trabalho realizado por NARDY et al (2011), sobre a possibilidade de implantação de um Sistema de Gerenciamento Ambiental em IES os autores constataram que é possível desenvolver a avaliação de desempenho ambiental. Estes verificaram e analisaram os consumos de água, energia, geração de resíduos sólidos, tratamentos de efluentes e, também realizaram o inventário corporativo das emissões de gases. 


\section{O papel desempenhado pelo CO dentro da qualidade do ar}

Os padrões de qualidade do ar têm por objetivo estabelecer limites máximos toleráveis de concentração de determinadas substâncias no ar, de modo que estas não venham a comprometer a saúde e o bem-estar da população (CAVALCANTI, 2010). A degradação da qualidade do ar está relacionada diretamente com a poluição atmosférica, uma vez que, através do nível de poluição na atmosfera é possível avaliar a qualidade do ar ambiente (GONÇALVES, 2008).

Atualmente o planeta passa por uma série de alterações climáticas, muitas das quais atribuídas ao descarte acelerado de substâncias exógenas e tóxicas ao meio ambiente. Dessas substâncias emitidas destacam-se os gases, os quais são gerados continuamente, e muitas vezes em concentrações acima dos limites estabelecidos por lei, causando problemas à saúde da população residente no entorno da fonte emissora ou mesmo são levados a regiões distantes por meio da dispersão atmosférica.

Conforme o Ministério do Meio Ambiente (MMA, 2013) os processos industriais e de geração de energia, os veículos automotores e as queimadas são, dentre as atividades antrópicas, as maiores causas da introdução de substâncias poluentes à atmosfera, muitas delas tóxicas.

A qualidade do ar é caracterizada por meio da utilização de indicadores diversos, geralmente expressos pela concentração de um dado poluente em um determinado intervalo de tempo. Os indicadores mais utilizados são os seguintes poluentes: $\mathrm{SO}_{2}$, $\mathrm{NO}$, $\mathrm{CO}$ e MP (MARIZ, 2013).

Os padrões de qualidade do ar definem legalmente o nível máximo de concentração de um determinado poluente na atmosfera, estabelecendo como limite a concentração que garanta a proteção da saúde do homem e do meio ambiente. Os padrões nacionais foram estabelecidos pelo Instituto Brasileiro de Meio Ambiente (IBAMA) e aprovados pelo Conselho Nacional de Meio Ambiente (CONAMA), por meio da Resolução CONAMA No. 03/90. Os parâmetros regulamentados são os seguintes: MP, fumaça, dióxido de enxofre (SO2), CO, ozônio (O3) e NOx (MARIZ, 2013).

Desses gases emitidos destaca-se o CO, que tem como principal fonte a frota veicular, especificadamente os veículos leves (automotores de passeio e de uso misto), movidos a gasolina e álcool. O CO é responsável por inúmeros efeitos negativos à saúde, apresentando afinidade pela hemoglobina 240 vezes maior que a do oxigênio, o que faz com que o mesmo possa saturar uma grande quantidade de moléculas de hemoglobina, diminuindo a capacidade do sangue de transportar oxigênio. Atua também, sobre o sistema respiratório, podendo vir a causar falta de ar e alergias em geral (TEIXEIRA et al., 2008).

O progressivo aumento do volume de tráfego rodoviário, principalmente nos centros urbanos, resulta majoritariamente da dependência da população em relação ao uso do automóvel. Este fato tem provocado um consumo excessivo e ineficiente de energia, bem como a diminuição das condições de mobilidade e da qualidade de vida urbana (MARTINS, 2005). O desenvolvimento das áreas urbanas e o aumento do poder de compra da população sugerem uma utilização permanente do transporte rodoviário individual, conduzindo ao inevitável crescimento do parque automobilístico.

Segundo o Programa de Controle de Poluição do Ar por Veículos Automotores (PROCONVE, 2009), as crescentes taxas de urbanização, a deficiência de políticas públicas de transporte em massa, inclusive com incentivos à produção e consumo de veículos, têm implicado num aumento expressivo da motorização individual (automóveis e motociclos) e apontam para cenários futuros de uma ainda maior expansão dessa frota. O mesmo vale para a frota de veículos pesados.

As emissões provenientes do tráfego são oriundas do processo de combustão, com a consequente libertação pelo tubo de escape de diversos poluentes, para além da própria evaporação do combustível ou de outros produtos associados ao funcionamento do veículo. As duas últimas décadas têm sido importantes no que diz respeito a avanços tecnológicos, a exemplo disso, tem-se a introdução dos catalisadores. A indústria automobilística tem vindo a melhorar a eficiência de consumo dos veículos com a introdução de normas mais rigorosas em matéria de emissões (OSSES e URRUTIA, 2002). 
Embora as emissões provenientes dos veículos e as fontes pontuais tenham sido reduzidas por meio da utilização de combustíveis menos poluentes e do avanço da tecnologia, as zonas urbanas ainda apresentam um crescente stress ambiental, nomeadamente, perdas de espaços abertos, aumento de trafego automóvel e degradação da qualidade do ar. A presença deste stress mostra que o avanço tecnológico não é a única solução para a degradação da qualidade do ar urbano, apontando para a necessidade desenvolver planos ou estratégias no sentido do melhoramento dos vários níveis da estrutura urbana (BORREGO et al., 2008).

A determinação da qualidade do ar está restrita a um grupo de poluentes, quer por sua maior frequência de ocorrência, quer pelos efeitos adversos que causam ao meio ambiente (MARIZ, 2013).

Destacando-se o CO, que é um contaminante quase inteiramente produzido e emitido na atmosfera como subproduto da combustão incompleta de combustíveis fósseis, é um gás incolor, inodoro e tóxico, o que o torna de difícil percepção (TEXEIRA et al., 2008).

As concentrações mais altas de CO ocorrem quando da partida do motor frio, em marcha lenta, nos sinais de trânsito e interseções rodoviárias e em engarrafamentos. Disso decorre como consequência os motores serem a principal fonte de emissão de CO para a atmosfera. As concentrações do CO na atmosfera urbana dependem da densidade do tráfego das ruas, da manutenção do motor e das condições meteorológica (VIEIRA, 2009).

Em níveis baixos, o CO pode produzir sintomas não específicos, parecidos com a gripe. Sintomas como vertigens, dor de cabeça, náuseas, zumbido nos ouvidos, palpitação cardíaca e respiração irregular podem ocorrer para níveis de carboxihemoglobina entre 2 e 10\% . O grau em que estes sintomas ocorrem depende do estado de saúde e da sensibilidade dos indivíduos, logo as respostas específicas a uma dada concentração variam de indivíduo para indivíduo (BRICKUS, 1997).

Portanto, a prevenção dos efeitos deletérios da poluição atmosférica passa por identificar (para os principais contaminantes) os níveis minimamente seguros de proteção das condições de saúde da população, expressos em termos de valores de sua concentração no ar. Estes níveis constituem-se na referência básica para o estabelecimento de padrões de qualidade do ar (PQA).

Para o Conselho Nacional do Meio Ambiente (CONAMA), em sua Resolução 03/1990 (Art. $1^{\circ}$ ), "são padrões de qualidade do ar as concentrações de poluentes atmosféricos que, ultrapassadas, poderão afetar a saúde, a segurança e o bem-estar da população, bem como ocasionar danos à flora e à fauna, aos materiais e ao meio ambiente em geral”.

Estes aspectos deixam evidente que as IES devem combater os impactos ambientais gerados, haja vista, as mesmas serem um nicho de pesquisa e desenvolvimento, servindo de exemplo no cumprimento da legislação, saindo do campo teórico para a prática.

Rodrigues (2013) avaliou a qualidade do ar em longo prazo na cidade de Lisboa, avaliando os efeitos dos principais poluentes na atmosfera. A abordagem definida pela legislação para o CO, mostrou que não existia concentrações superiores ao valor limite (6.846 partes por milhão ppm) estabelecido para a proteção da saúde humana, nas estações em estudo, no período de 2001 a 2011.

Rodrigues (2013) ainda observou que, as estações que atingiram concentrações mais elevadas de CO, foram as que possuíam um maior tráfego de veículos, evidenciando a contribuição das emissões de automóveis para o aumento das concentrações de CO. Em suas observações ainda, verificou que nos meses de Outono e Inverno as concentrações de CO são mais elevadas que na Primavera e Verão, possivelmente por nos meses de Outono e Inverno existir acumulação de poluentes, tal deve-se a estabilidade atmosférica existente, que condiciona a dispersão de poluentes. Contudo, o CO apresentou claramente uma diminuição das suas concentrações no Verão, começando a decrescer na Primavera, este fato indica um consumo deste poluente no verão, eventualmente por via fotoquímica.

No Brasil registrou-se um rápido aumento das emissões de poluentes atmosféricos nas áreas urbanas nas últimas décadas. Em algumas cidades, notadamente na Região Metropolitana de São Paulo (RMSP), os níveis de concentração de poluentes passaram a atingir patamares que colocavam em risco a saúde das pessoas com frequência alarmante, obrigando as autoridades a tomar ações para controlar este problema emergente (MENDES, 2004). 
A RMSP possui uma frota de seis milhões de veículos leves, onde as principais fontes de poluição do ar são os automóveis, seguidos por processos industriais, queima de resíduos, movimentação de combustíveis, entre outras (CETESB, 2002).

Em termos de emissões relativas por fontes, os dados da RMSP, gerados pela CETESB (2006) permitem uma boa noção do que ocorre nos grandes centros urbanos. Segundo esses dados os automóveis e motocicletas respondem juntos por cerca de $90 \%$ das emissões de CO e 70\% das emissões de HC. Os veículos pesados a diesel são responsáveis pela maioria das emissões de NOx, com participação destacada nas emissões de material particulado e de SOx.

Em 2012, além das estações de monitoramento da RMSP, o CO foi monitorado nas estações em Campinas (Centro) e São Jose dos Campos, alcançando a media máxima de 8 horas de 3,5 ppm e 3,4 ppm, respectivamente, valores esses bem abaixo do Parâmetro de Qualidade do Ar (CETESB, 2012).

Teixeira (2008), em seu trabalho estudou as emissões de origem veicular na Região Metropolitana de Porto Alegre (RMPA) que está localizada na área leste-central do Estado do Rio Grande do Sul, no sul do Brasil. A região é formada por 31 cidades distribuídas em uma área de 9.825,61 km2, onde aproximadamente 36\% (3,7 milhões de habitantes) da população do estado está concentrada, sendo constituída como o eixo mais urbanizado do estado. Esta região sofre influência antropogênica de diferentes origens: fontes estacionárias, como refinarias de óleos, siderúrgicas, petroquímica, termoelétrica e queima de resíduo hospitalar e, de maior relevância, fontes móveis. Segundo a Fundação Estadual de Proteção Ambiental estima-se que a frota circulante na RMPA corresponda a 20\% do total das 3,1 milhões de unidades de todo o estado.

Em sua pesquisa Teixeira (2008), inicialmente realizou um levantamento organizacional da frota veicular da RMPA, em seguida através de cálculos obteve as emissões totais da região. A distribuição do perfil da frota veicular por tipos de combustíveis em número de veículos na RMPA em 2004, foi composta por 1.166.914 veículos, destes 979.113 movidos a gasolina, 79.345 a álcool, 84.925 a diesel, 14.897 a gás natural veicular e 8.632 com tecnologia flex. Conforme pode ser observado nos dados apresentados, os veículos com propulsão a gasolina correspondem à maioria da frota veicular, $85 \%$. Ao calcular as emissões totais, esse pesquisador observou que os veículos a gasolina e a diesel (129,8 e 35,11 t.ano-1, respectivamente) mostraram contribuição mais significativa nas emissões de CO. No entanto, a emissão deste composto por veículos a gasolina foi bem mais elevada que por veículo a álcool (16,97 t.ano-1).

Diversas cidades além de realizar pesquisas voltadas para o meio ambiente vêm adotando medidas para reduções de emissões. A cidade do México, com seus 19,7 milhões de habitantes, vem adotando, desde a década de 1990, um bem sucedido programa de redução das emissões veiculares. Após atingir índices de poluição gravíssimos, principalmente de $\mathrm{CO}$, gerando mais de 110 mil internações e 4.000 mortes por ano, a sociedade se conscientizou do problema. As ações foram voltadas para exigência de uso de catalisadores, controle de emissões dos veículos, vistoria veicular e restrições de circulação de automóveis por área e horários. Em uma segunda fase, houve ações voltadas para melhoria e expansão do transporte coletivo (o próprio metrô da Cidade do México teve início na mesma época do Metrô de São Paulo e hoje possui uma malha ferroviária 4 vezes maior) além de medidas voltadas para o controle da expansão da mancha urbana e reorganização espacial das atividades. As medidas surtiram efeitos bastante positivos, apesar do problema ainda existir dado o tamanho da região metropolitana (IPEA, 2011).

No Brasil também se têm observado uma clara redução das emissões de vários poluentes locais, como CO, NO, HC e PTS. Essa redução influência os índices de qualidade do ar nos grandes centros urbanos. De acordo com o relatório do IBGE Indicadores de Desenvolvimento Sustentável, de 2010, houve uma tendência estacionária ou de declínio das concentrações máxima e média de poluentes atmosféricos nos pontos de monitoramento da maior parte das regiões metropolitanas brasileiras. A publicação imputa esse resultado, pelo menos em parte, ao Programa de Redução de Emissões de Veículos Automotores (PROCONVE, 2009).

\section{A influência das características urbanas e geográficas na qualidade do ar}

A atmosfera influencia a dispersão dos poluentes e existem vários fatores que afetam esse comportamento, os quais podem ser categorizados em termos de características do local de 
emissão, características do poluente emitido, condições meteorológicas e efeitos do terreno (TESSAROLO, 2012).

O tamanho da fonte é um fator que determina como o poluente irá se dispersar na atmosfera, uma vez que os movimentos do ar acontecem em muitas escalas de tamanho. $\mathrm{O}$ movimento horizontal do vento ao redor faz com que os poluentes desloquem-se sua direção, possibilitando sua diluição e dispersão. Seguindo na direção do vento dominante, quanto maior a distância entre a fonte emissora e a fonte receptora, maior será o volume de ar disponível para a diluição dos contaminantes (TESSAROLO, 2012).

Em ambiente urbano, o setor dos transportes distingue-se das restantes fontes de poluição, devido à proximidade entre as emissões e a população, o que aumenta o nível de exposição aos poluentes emitidos por este setor, como também devido às fracas condições de dispersão dos poluentes presentes nos centros urbanos (VARDOULAKIS et al., 2003).

A dispersão é limitada pelo tempo de residência do poluente na atmosfera. As espécies hidrossolúveis, as quais podem se dissolver nas gotículas de água para formação de nuvens ou podem ser removidas da atmosfera através de precipitação, geralmente possuem um tempo de residência atmosférico de poucos dias. Já os poluentes quimicamente instáveis apresentam tempos de residência variados. Por exemplo, o tempo médio de vida do CO antes de reagir com os radicais hidroxila é de, aproximadamente, um mês (TESSAROLO, 2012).

Os parâmetros meteorológicos também influenciam na dispersão dos poluentes, tais como: velocidade e direção do vento, turbulência e estabilidade. O aumento da velocidade do vento faz com que os poluentes mudem para a direção horizontal mais rapidamente, resultando em uma diminuição em sua altura e, consequentemente, no aumento da concentração de poluentes na superfície. De outra forma, o aumento na velocidade do vento também proporciona um aumento na taxa de diluição do poluente, tendendo a diminuir a concentração nessa direção. Já a turbulência, ou seja, os movimento altamente aleatório e irregular do fluido, faz com que o ar poluído seja misturado e, por consequência, diluído. E a estabilidade é definida como sendo a tendência da atmosfera em propagar movimentos verticais ou resistir a eles e é influenciada tanto pela velocidade do vento, quanto pela taxa de variação da temperatura na vertical,de forma geral, como os movimentos verticais são intensificados com a flutuabilidade, os poluentes são dispersos mais rapidamente em condições de instabilidade atmosférica (TESSAROLO, 2012).

A estrutura do meio no qual o poluente é emitido também afeta a dispersão. O processo de expansão vertical observado na maioria das cidades brasileiras (antes visto apenas nas grandes metrópoles nacionais e regionais) passa agora habitualmente, a ser visto também em cidades médias e pequenas, e sugere que seu entendimento esteja contextualizado ao processo de urbanização de uma cidade (SOUZA e COSTA, 1998). Em ambientes com elevada urbanização, a massa do material é capaz de absorver e irradiar calor em uma taxa maior que a da área ao redor, causando um fenômeno denominado ilha de calor. Por causa desse efeito, a estabilidade da atmosfera local é alterada, ficando menor do que sobre as redondezas, as altas construções acabam transformando-se em obstáculos à circulação do ar, esse resfriamento radiativo dificulta a dispersão dos poluentes emitidos no período noturno ao nível do solo (TESSAROLO, 2012).

Deve-se considerar, que nas situações de ventilação e mesmo de calmas, todo o contaminante lançado na camada de ar intra-urbana pelas atividades desenvolvidas nestes locais, notadamente pela emissão veicular de gases e ressuspensão veicular de material particulado, terá sua dispersão influenciada também pelas especificidades de verticalidade das quadras que compõem estes locais (MONTEIRO, 1978).

A presença de edifícios e sua disposição na malha urbana têm implicações ao nível da redução da velocidade do vento afetando deste modo à dispersão dos poluentes e consequentes acumulações dos mesmos (SANTOS, 2003).

A verticalização altera a rugosidade da superfície local, ora canalizando os ventos, ora atuando como barreiras à livre circulação do ar. Por outro lado, deve ser relembrado o fato dos prédios agirem como "armazenadores térmicos", modificando as trocas de energia, propiciando assim, a criação de campos térmicos diferenciados. Destas condições resulta que, em ocasiões sinópticas de estagnação atmosférica, a qualidade do ar pode ficar comprometida, uma vez que a estrutura topográfica edificada tende a propiciar o confinamento dos poluentes lançados pelo 
intenso tráfego de automóvel que nela circulam, funcionando as ruas como verdadeiros vales, cujas vertentes são constituídas pelas paredes dos edifícios (PINTO et al., 2009).

Uma maneira de diminuir esses impactos ambientais, provocados pela verticalização, é a arborização das cidades. A vegetação possui uma importante função na melhoria e estabilidade microclimática devido à redução das amplitudes térmicas, redução da insolação direta, ampliação das taxas de evapotranspiração e redução da velocidade dos ventos (MILANO, 2000).

Segundo Silva (2012), em Campina Grande, a verticalização é mais expressiva nos bairros: Catolé, Alto Branco, Mirante, Prata, Bela Vista, Centro, localizados no setor leste e expandindo também para a periferia que é o caso do bairro de Bodocongó, localizado no setor oeste da cidade, onde o campus I, da UFCG está situado.

Esse processo também é visivelmente observado dentro do Campus I da UFCG, onde nos últimos anos houve um aumento expressivo na verticalização do local. Entretanto, apesar do aumento nas construções, o campus possui ainda uma grande área aberta, com uma boa arborização.

\section{Conclusões}

Diante do exposto, pode-se concluir que é possível observar mudanças no cenário veicular do país, bem como do Campus I da UFCG, a começar do aumento da frota veicular e no avanço tecnológico dos combustíveis (álcool e gasolina) e dos veículos (catalisadores, por exemplo).

Nota-se também, que além das grandes emissões de monóxido de carbono emitidas pelo número elevado de veículos em circulação, outro fator de bastante relevância para a contaminação atmosférica é a verticalização dos ambientes, que favorece o aprisionamento do poluente, para diminuir esse aprisionamento, melhorar a qualidade do ar e consequentemente a qualidade de vida, precisa-se investir e incentivar a arborização das cidades.

\section{Use of carbon monoxide, as an indicator of air quality in the Federal University of Campina Grande.}

Abstract: To say that quality of life is talk of air quality, considering this a pattern indicative of atmospheric conditions in a particular region. A country or a city that has an air quality index (IQAr) classified as inadequate hence will have a population with serious health problems (cough, fatigue, eye irritation, nose and throat). Vehicles (cars, buses, trucks, etc.) and motorcycles are considered significant sources of carbon monoxide, since even parked are emitting sources, representing large portion of this gas in the atmosphere. Studies show that vehicle emissions are responsible for the degree of pollution in towns and cities. Brazil currently has 2,378 higher education institutions ( $\mathrm{HEI}$ ), which are distributed throughout the country. HEI these are social organizations and as such express a certain way the structure and mode of operation of society as a whole. This profile, leads them to be compared to small urban centers, involving an infrastructure compared to medium and small cities. In this context, the Federal University of Campina Grande (UFCG), is a relevant institution for the state of Paraiba, since, it has an average daily flow of 11,873 people, accounting for $3.07 \%$ of the 386,000 citizens of Campina Grande, whose fleet vehicle is 147,423 vehicles and 78,551 motorcycles. Vehicles are considered mobile sources of air pollution are responsible for the generation of carbon monoxide (CO), a gas which in high concentrations causes negative health effect.

Keywords: Universities; Gas Emissions.

\section{Referências bibliográficas}

BORREGO, C.; Miranda, A. I. Avaliação da Qualidade do Ar da Região Norte: uma perspectiva histórica, 2000 - 2007, Porto. Universidade de Aveiro, Comissão de Coordenação e Desenvolvimento da região Norte (2008). 
BRAGA, A. L. F. Poluição Atmosférica e seus Efeitos na Saúde Humana. Revista USP, CCS, n. 51, p. 58-71, 2001.

BRICKUS, L. S.; AQUINO NETO, F. R. A qualidade do ar de interiores e a química, Química Nova, V. 20, N.4: 1997.

CAVALCANTI, P.M.P.S., Modelo de Gestao da Qualidade do Ar - Abordagem Preventiva e Corretiva, Tese (Doutorado em Planejamento Energetico),, Universidade federal do Rio de Janeiro, RJ, 2010.

[CONAMA] CONSELHO NACIONAL DO MEIO AMBIENTE. Resolução No 03, de 28 de

Junho de $1990.1990 . \quad$ Disponível em

http://www.mma.gov.br/port/conama/legiabre.cfm?codlegi=660. Acesso em novembro 2013

[CETESB] COMPANHIA DE TECNOLOGIA DE SANEAMENTO AMBIENTAL. A participação dos veículos automotores na poluição atmosférica. São Paulo: CETESB, 1985.

.Relatorio Anual da Qualidade do ar no Estado de São Paulo - 2001. São Paulo, 2002.

.Relatorio Anual da Qualidade do ar no Estado de São Paulo - 2005. São Paulo, 2006.

.Relatorio Anual da Qualidade do ar no Estado de São Paulo - 2011. São Paulo, 2012.

[DETRAN] DEPARTAMENTO ESTADUAL DE TRÂNSITO. Frota de veículos. Disponível em: http://www.detran.pb.gov.br/index.php/estatisticas.html Acesso em: 19 agosto 2014.

GONÇALVES, L. P. Impacto da combustão Doméstica na Qualidade do Ar. Tese (Mestrado em Engenharia do Ambiente)- Universidade de Aveiro, Departamento de Ambiente e Ordenamento. Aveiro, 2008.

[IBGE] INSTITUTO BRASILEIRO DE GEOGRAFIA E ESTATÍSTICA. Censo das cidades. Disponível em: http://www.ibge.gov.br/cidades.

[IPEA] INSTITUTO DE PESQUISA ECONÔMICA APLICADA - Comunicado do IPEA, Poluição Veicular Atmosferica. Nº113 - 22 de setembro de 2011.

[INEP] INSTITUTO NACIONAL DE ESTUDOS E PESQUISAS EDUCACIONAIS-Censo da Educação Superior 2010 - divulgação dos principais resultados do censo da educação superior 2010.

MARIZ, T. F. Avaliação do desempenho ambiental de instituição de ensino superior: modelo com indicadores. $104 \mathrm{f}$.Tese. (Doutorado em Engenharia Química) - Universidade Federal de Campina Grande. 2013.

MARTINS, A. P. Avaliação da Qualidade do Ar em Lisboa. Estações Urbanas de Tráfego. Departamento de Ambiente e Ordenamento: Universidade de Aveiro, Aveiro, 2005.

MARTINS, C. B. O ensino superior brasileiro nos anos 90. São Paulo em perspectiva. v.14. n.1. 41-60. 2000.

MENDES, E. F.; Avaliação de programas de controle de poluição atmosférica por veículos leves no Brasil; 179 f. Tese (Doutorado em Ciencias em Planejamento Energetico) Universidade Federal do Rio de Janeiro, Rio de Janeiro, 2004.

[MMA] MINISTÉRIO DO MEIO AMBIENTE. Disponível em: http://www.mma.gov.br/cidades-sustentaveis/qualidade-do-ar Acessado em: 23 de setembro de 2013.

MILANO, M.S. Avaliação quali-quantitativa e manejo da arborização urbana de MaringáPR. UFPR,Tese ( Doutorado em Ciências Florestais) - Universidade Federal do Paraná, Curitiba, 2000.

MONTEIRO, C.A. F. Derivações antropogênicas dos geossistemas terrestres no Brasil e alterações climáticas: perspectivas urbanas e agrárias ao problema da elaboração de 
modelos de avaliação. Anais do Simpósio sobre Comunidades Vegetais como Unidades Biológica, Faunística e Econômica. São Paulo.1978.

NARDY, M.B.C.; CUNHA,M.E.G.; BICHARA, J.; POLI, M. Análise de Processos em IES Visando a Implantação de um SGA. Revista de Ciências Gerenciais. IPADE. Vol. 14, No. 12, Ano 2011

OLIVEIRA, B. C. de., AMORIM, C. Diagnóstico e caracterização dos aspectos ambientais para implantação do sistema de gestão ambiental: caso PUC minas campus coração eucarístico, V Seminário PUC Minas, 2010.

OSSES, R.; URRUTIA, C. (2002). Hot Emissions Model for mobile Sources: Applications to the Metropolitan Region of the City of Santiago, Chile. Journal of the Air \& Waste Management Association. Vol. 52. pp 167-174.

PINTO, D.; GASPAR, P.; GANHO, N.;CORDEIRO,A.M.R. Agentes meteorológicos e qualidade do ar na cidade de Coimbra (Portugal). I Congresso de desenvolvimento regional de Cabo Verde, Cabo Verde, 2009.

[PROCONVE] PROGRAMA DE CONTROLE DE POLUIÇÃO DO AR POR VEÍCULOS AUTOMOTORES. Relatório de emissão 2009. Disponível em: $<$ http://www.mma.gov.br/estruturas/163/_arquivos/proconve_163.pdf>

RODRIGUES, A. F. S. B. Avaliação da qualidade do ar a longo prazo da cidade de Lisboa. 87 f. Dissertação (Engenharia do Ambiente, perfil de Ordenamento do Território e Impactes Ambientais), Universidade Nova de Lisboa. 2013.

SANTOS, R. M. Avaliação da Qualidade do Ar na Área Metropolitana do Porto, 1999-2003. Tese (Mestrado em Engenharia do Ambiente)- Universidade de Aveiro, Porto, 2003.

SOUZA, A. A. M.; COSTA, S.M. F. O uso de fotografias aéreas para a análise do processo de verticalização na cidade de São José dos Campos - SP. In: Anais IX Simpósio Brasileiro de Sensoriamento Remoto, Santos, Brasil, 11-18 setembro 1998.

SILVA, S.C.; Processo de Verticalização da Cidade de Campina Grande. Trabalho de Conclusão de Curso de Licenciatura em Geografía. Universidade Federal da Paraíba, Campina Grande,PB, 2012.

TESSAROLO, L.F.; Análise da qualidade do ar em três locais no Estado de São Paulo com características distintas de desenvolvimento econômico; 192f. Dissertação (Mestrado em em Meteorologia) - INPE, São josé dos Campos, 2012.

TEIXEIRA, E. C., FELTES, S., SANTANA, E. R. R. de. Estudo das emissões de fontes móveis na região metropolitana de Porto Alegre, Química Nova, V. 31, №.: 2008.

TAUCHEN, J; BRANDLI, L.L. A gestão ambiental em instituições de ensino superior: modelo para implantação em campus universitário. Revista de Gestão e Produção. 2006.

VARDOULAKIS, S.; Fisher, B.; Pericleous, K.; Gonzalez.Flesca, N. (2003). Modelling air quality in street canyons: a review. Atmospheric Environment. Vol. 37, Issue 2, pp 26592677.

VIEIRA, N. R. Poluição do Ar. Rio de Janeiro: E-papers, p 220. 2009. 